\title{
Inactivation of Cdc42 in embryonic brain results in hydrocephalus with ependymal cell defects in mice
}

\author{
Xu Peng ${ }^{1 凹}$, Qiong Lin ${ }^{2}$, Yang Liu ${ }^{1}$, Yixin Jin ${ }^{1}$, Joseph E. Druso ${ }^{2}$, Marc A. Antonyak ${ }^{2}$, Jun-Lin Guan ${ }^{3}$, \\ Richard A. Cerione ${ }^{2}$ \\ ${ }^{1}$ Department of Systems Biology and Translational Medicine, College of Medicine, Texas A\&M Health Science Center, Temple, \\ TX 76504, USA \\ ${ }^{2}$ Department of Molecular Medicine, Cornell University, Ithaca, NY 14853, USA \\ ${ }^{3}$ Department of Internal Medicine-Division of Molecular Medicine and Genetics and Department of Cell and Developmental \\ Biology, University of Michigan Medical School, Ann Arbor, MI 48109, USA \\ $\square$ Correspondence: xpeng@medicine.tamhsc.edu (X. Peng), rac1@cornell.edu (R. A. Cerione) \\ Received September 5, 2012 Accepted October 11, 2012
}

\section{ABSTRACT}

The establishment of a polarized cellular morphology is essential for a variety of processes including neural tube morphogenesis and the development of the brain. Cdc42 is a Ras-related GTPase that plays an essential role in controlling cell polarity through the regulation of the actin and microtubule cytoskeleton architecture. Previous studies have shown that $\mathrm{Cdc42}$ plays an indispensable role in telencephalon development in earlier embryo developmental stage (before E12.5). However, the functions of Cdc42 in other parts of brain in later embryo developmental stage or in adult brain remain unclear. Thus, in order to address the role of $\mathrm{Cdc42}$ in the whole brain in later embryo developmental stage or in adulthood, we used Cre/loxP technology to generate two lines of tissuespecific Cdc42-knock-out mice. Inactivation of Cdc42 was achieved in neuroepithelial cells by crossing Cdc42/ flox mice with Nestin- Cre mice and resulted in hydrocephalus, causing death to occur within the postnatal stage. Histological analyses of the brains from these mice showed that ependymal cell differentiation was disrupted, resulting in aqueductal stenosis. Deletion of Cdc42 in the cerebral cortex also induced obvious defects in interkinetic nuclear migration and hypoplasia. To further explore the role of Cdc42 in adult mice brain, we examined the effects of knocking-out Cdc42 in radial glial cells by crossing Cdc42/flox mice with human glial fibrillary acidic protein (GFAP)-Cre mice. Inactivation of Cdc42 in radial glial cells resulted in hydrocephalus and ependymal cell denudation. Taken together, these results highlight the importance of Cdc42 for ependymal cell differentiation and maintaining, and suggest that these functions likely contribute to the essential roles played by Cdc42 in the development of the brain.

KEYWORDS Cdc42, small GTPase, neuron, glial cell, polarity, development.

\section{INTRODUCTION}

Tube morphogenesis is important for multicellular organ development and consequently disrupting this process can lead to serious diseases such as obstructive hydrocephalus, kidney cysts, and aneurysms and vaso-occlusive disease (Lubarsky and Krasnow, 2003). The neural tube arises from a polarized epithelium called the neural plate and gradually folds up to form a hollow tube. Once the hollow tube is closed, the inside cavity will eventually develop into the brain's four ventricles and the spinal cord central canal (Wallingford, 2006). Polarized ependymal cells line the inner face of the ventricles as well as the spinal cord central canal, and both the establishment and maintenance of cell polarity are critical for neural tube formation and brain development (Del Bigio, 1995).

Cdc42 is a small GTPase which cycles between an inactive (GDP-bound) state and an active (GTP-bound) state and thereby acts as a molecular switch that regulates a vast array of cellular activities, especially in the establishment of 
cell polarity (Erickson and Cerione, 2001; Etienne-Manneville and Hall, 2002; Cerione, 2004; Etienne-Manneville, 2004). Cdc42 was first identified in yeast as a master regulator of cell polarization, and in humans as a participant in epidermal growth factor (EGF)-coupled signaling (Johnson and Pringle, 1990; Shinjo et al., 1990). When Cdc42 was mutated in yeast cells, the cells lost their ability to establish the necessary polarity for the assembly of the bud site (Johnson and Pringle, 1990). Subsequent studies showed that the disruption of Cdc42 function interfered with asymmetric mitosis and spindle orientation in C. elegans (Gotta et al., 2001). Over-expression of a dominant-negative (DN) form of Cdc42 caused changes in the polarized morphology of cells and the disruption of epithelial apical-basal elongation in Drosophila (Hutterer et al., 2004). In mammalian cells, Cdc42 regulates the formation of filopodia and focal adhesion complexes as well as controls polarity signals that are required for directed migration (Nobes and Hall, 1995). In addition, Cdc42 plays an essential role in maintaining pancreatic apical cell polarity and tubulogenesis (Kesavan et al., 2009). Therefore, the regulatory role played by $\mathrm{Cdc} 42$ in the establishment of cell polarity has been highly conserved throughout evolution.

The establishment of cell polarization is a sophisticated biological process which requires the coordination of actin and microtubule cytoskeletal reorganization as well as vesicle trafficking to deliver different proteins to specific cellular sites in an asymmetric fashion (Etienne-Manneville, 2004). Accumulating evidence suggests that $\mathrm{Cdc} 42$ plays a key role in the regulation of microtubule rearrangement. Activated Cdc42 recruits Par6 and the atypical protein kinase C (aPKC) to the leading edge and helps to stabilize microtubules (Etienne-Manneville and Hall, 2001). Cdc42 can also interact with IQGAP1 and bring microtubule-plus ends to the plasma membrane which may help the reorientation of the microtubule cytoskeleton and centrosome (Fukata et al., 2002). In addition, Cdc42 has been shown to play a critical role in the regulation of actin polymerization through two effectors, p21Activated Kinase (PAK) and Wiskott Aldrich Syndrome protein (WASp) (Prehoda et al., 2000; Etienne-Manneville and Hall, 2003). PAK is one of the better-characterized downstream effectors of Cdc42, as GTP-bound Cdc42 interacts with PAK and results in the activation of its kinase activity (Bokoch, 2003). Activated PAK can inhibit cofilin and promote actin polymerization (Edwards et al., 1999). GTP-bound Cdc42 also binds to WASp and activates the Arp2/3 complex, influencing actin polymerization and ultimately leading to filopodia formation (Machesky and Insall, 1999; Kim et al., 2000; Prehoda et al., 2000). Moreover, Cdc42 can influence intracellular trafficking events through its interactions with Y-COP (Wu et al., 2000). These various findings suggest that Cdc42 regulates multiple steps during the establishment of cell polarity.

Neurons originate as spherical cells and then generate multiple immature neurites. One of the neurites will elongate rapidly to form the long axon and the others will grow slowly to become multiple short dendrites (Govek et al., 2005). The establishment of neuronal polarization has been studied extensively and Cdc42 has been shown to play an essential role in this process (Luo et al., 1994; Schwamborn and Puschel, 2004; Garvalov et al., 2007). Activation of Cdc42 is required for neurite growth, and overexpression of dominantnegative Cdc42 mutants inhibits neurite growth (Sarner et al., 2000). Fluorescence resonance energy transfer (FRET) analysis showed that Cdc42 was activated in nerve growth factor (NGF)-stimulated neurite outgrowth in PC12 cells (Aoki et al., 2004). In line with its critical role in neurite growth, Cdc42 also plays a pivotal role in axon formation and pathfinding. Over-expression of the Cdc42(F28L) mutant (a form of Cdc42 that is capable of spontaneous GDP-GTP exchange and functions as a dominant-active mutant) or knocking-down Cdc42 by shRNA can induce or disrupt, respectively, the formation of axons in rat hippocampal neurons (Schwamborn and Puschel, 2004). Interference with Cdc42 function in Drosophila results in axon path-finding defects and leaves the axon unable to reach and recognize its target tissues (Kim et al., 2002). Consistent with its important in vitro functions in different kind of cells, inactivation of Cdc42 results in mouse embryonic lethality on E6.5 before nervous system development (Chen et al., 2000). To overcome this hurdle and study the functions of $\mathrm{Cdc} 42$ in neurons, two mouse lines in which Cdc42 was inactivated in the embryonic cerebral cortex by the Cre/loxp system were generated independently (Cappello et al., 2006; Chen et al., 2006). The deletion of Cdc42 in neural progenitor cells changed ventral neural progenitor fate and increased basal progenitor mitosis (Cappello et al., 2006). Due to the inactivation of Cdc42, two cerebral hemispheres failed to separate and caused holoprosencephaly (Chen et al., 2006). These two studies showed the importance of $\mathrm{Cdc} 42$ in the telencephalon in early mouse brain development. However, the role of $\mathrm{Cdc} 42$ in other parts of brain (in addition to telencephalon) in embryonic brain development and functions of $\mathrm{Cdc42}$ in adult mice brain remain unclear. To address these questions, we created a Cdc42/flox mouse line and then generated two $\mathrm{Cdc} 42$ conditional knockout mouse lines by crossing Cdc42/flox mice with either Nestin-Cre (Tronche et al., 1999) or human glial fibrillary acidic protein (GFAP)-Cre mice (Zhuo et al., 2001). Our data show that the inactivation of $\mathrm{Cdc} 42$ in neuroepithelial cells or radial glial cells resulted in hydrocephalus with ependymal cell defects and cerebral cortex hypoplasia, indicating that Cdc42 plays an indispensable role in mouse brain development.

\section{RESULTS}

\section{Generation of mice lacking Cdc42 in central nervous system}

To elucidate the physiological functions of $\mathrm{Cdc42}$ in vivo, we have generated a mouse strain with the $\mathrm{Cdc42}$ gene flanked by two loxP sites. A targeting vector containing exons $1-4$ of mouse Cdc42 was constructed (Fig. 1A). To avoid any possi- 
A
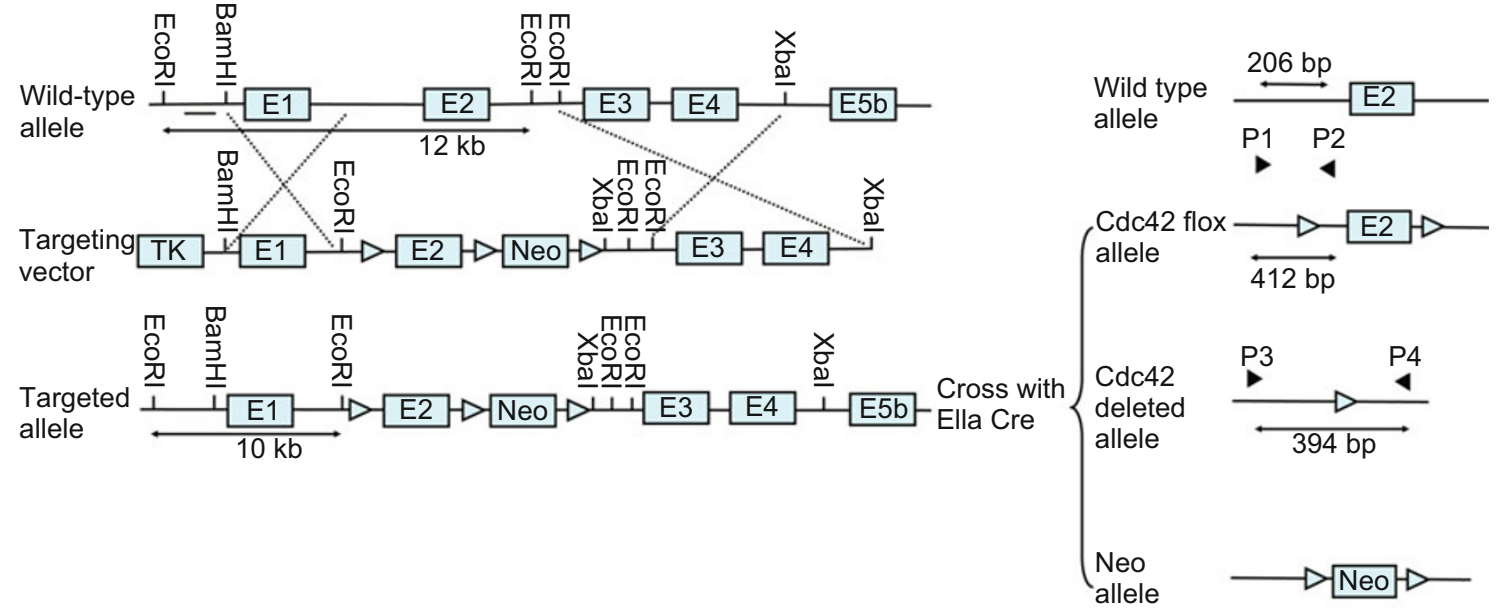

B

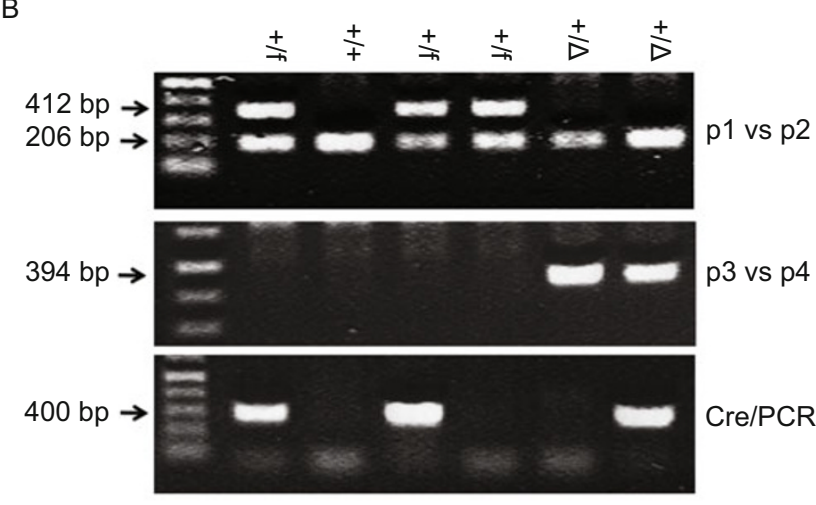

C

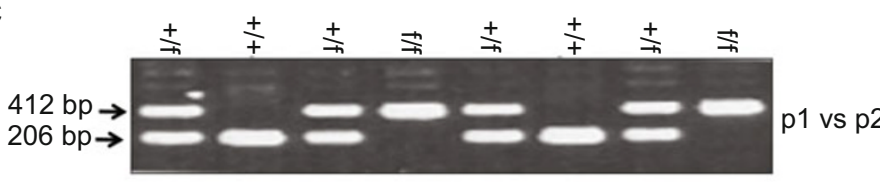

E

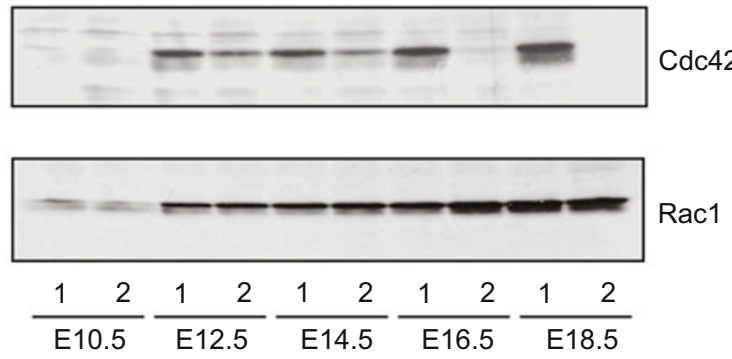

D

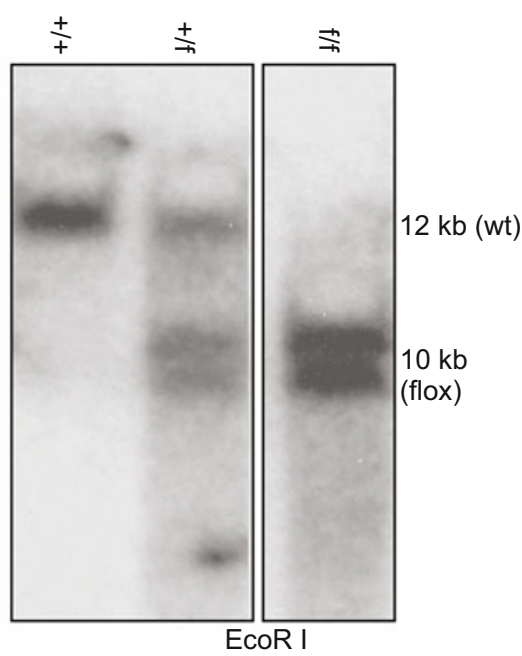

$\mathrm{F}$

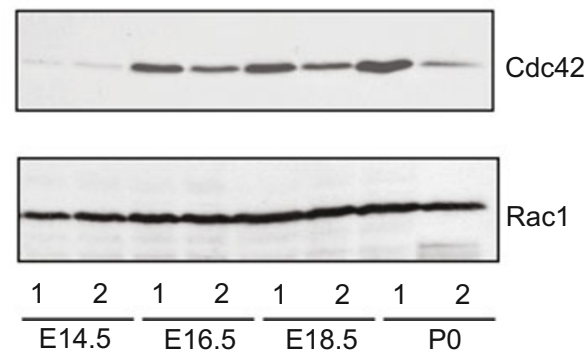

Figure 1. Generation of the Cdc42/flox mice. (A) Schematic of the targeting vector, genomic, and the loxP modified Cdc42 loci. Large filled triangles represent LoxP sites. Horizontal lines with arrows on both sides indicate the expected sizes of DNA bands in Southern blotting analysis of the genomic or targeted alleles. The relevant restriction sites are indicated. Three possible outcomes at the Cdc42 loci (flox, neo, $\Delta$ ) from crossing Ella-cre mice are shown. (B) An example of mice PCR genotyping. (C) Cdc42 ${ }^{\text {floxflox }}$ mice generated by Cdc42 flox/+ heterozygotes intercrossing. (D) Southern blotting analysis of the mice after digestion with EcoRI. (E) Tissue lyses were prepared from whole brain (E10.5 and E12.5) or front brain (E14.5, E16.5 and E18.5) of control (marked as 1) and CKO-Nes (marked as 2) mice. They were then analyzed by Western blotting using Cdc42 and Rac antibody, as indicated. (F) CFKO-GFAP (marked as 2) and control (marked as 1) brain lysates were analyzed by Western blotting using Cdc42 or Rac1 antibody.

ble interference with $\mathrm{Cdc42}$ gene expression, the neomycin cassette was removed by crossing $\mathrm{Cdc} 42^{\mathrm{flox}[\text { neo }] /+}$ mice with El-
la-Cre mice which carry the Cre transgene under the control of the Ella promoter and express Cre at the very early stages of 
embryogenesis (Lakso et al., 1996). The Cdc42 $2^{\text {flox/t+ } / E l l a-C r e ~}{ }^{+}$ mice were then crossed with C57BL/6 mice to separate the $\mathrm{Cdc4} 2^{\text {flox }}$ allele from the heterozygous Ella-Cre gene (Fig. 1B). $\mathrm{Cdc} 42^{\text {floxflox }}$ homozygous mice were then generated by mating between $\mathrm{Cdc}_{2} 2^{\mathrm{flox} /+}$ mice, and identified by PCR (Fig. 1C). All PCR results were confirmed by Southern blot analysis (Fig. 1D). Cdc4 $2^{\text {floxfllox }}$ homozygous mice breed normally and no overt phenotypes were exhibited, suggesting that the presence of the loxP sequence did not interfere with $\mathrm{Cdc} 42$ function.

To investigate the role of $\mathrm{Cdc} 42$ in brain development, we created Cdc42 conditional knockout mice in which $\mathrm{Cdc} 42$ expression was ablated in neuroepithelial cells by crossing Cdc42/flox mice with Nestin-Cre mice. In Nestin-Cre mice, Cre recombinase is controlled by a rat nestin promoter, and specifically expressed in neuronal and glial cell precursor (Tronche et al., 1999). To monitor the deletion efficiency of Nestin-Cre, we harvested embryonic brain (E10.5-E12.5) or cerebral cortex (E14.5-E18.5) from timed-pregnant females. Western blot analyses showed that the Cdc42 expression levels began to decrease by E12.5 and were essentially undetected on E16.5 in the front brain from Nestin-Cre conditional knockout mice (designated as CKO-Nes) (Fig 1E, upper panel), compared to Cdc42 $2^{\text {floxfllox }}$ mice (designated as Control). However, Rac-1 (a family member protein of Cdc42) expression in CKO-Nes brain was not affected (Fig. 1E, bottom panel). To examine the role of $\mathrm{Cdc} 42$ in adult mice brain, we also generated $\mathrm{Cdc} 42$ conditional knock-out mice in which $\mathrm{Cdc} 42$ expression was ablated in glial cells (designated as CKO-GFAP) by crossing Cdc42/ flox mice with GFAP-Cre mice. Western blot analysis showed that the $\mathrm{Cdc} 42$ expression levels were decreased beginning at E16.5, whereas Rac-1 expression was comparable to its levels in control and CKO-GFAP brains (Fig. 1F).

Inactivation of Cdc42 in neuroepithelial cells results in stenosis of the aqueduct of Sylvius and hydrocephaly

We screened 203 weaned mice and did not find any CKONes mice, suggesting that inactivation of $\mathrm{Cdc} 42$ either resulted in embryonic lethality or that the mice died at a very early postnatal stage. To determine when the CKO-Nes mice died, embryos were examined from E12.5 to E18.5. Near Mendelian ratios of four different genotype embryos were presented in whole embryo development (data not shown). The CKONes mice were born alive, but died within $72 \mathrm{~h}$ after birth. The newborn CKO-Nes pups were easily distinguishable from their control littermates by the lack of milk in their stomachs, reduced movement and difficulty in breathing (Fig. 2A and data not shown). Anatomical analysis of the brain demonstrated that all the cerebral cortical surfaces of CKO-Nes pups were flattened compared to the brains from control mice, and the size of olfactory bulbs was decreased slightly in CKO-Nes mice (Fig. $2 \mathrm{~B}$ ). More than half of the CKO-Nes pups also showed mild or moderate hemorrhage in the lateral ventricles of the brain (data not shown).

Histological analysis of sagittal sections displayed a striking morphological defect in the brains of the CKO-Nes mice. The
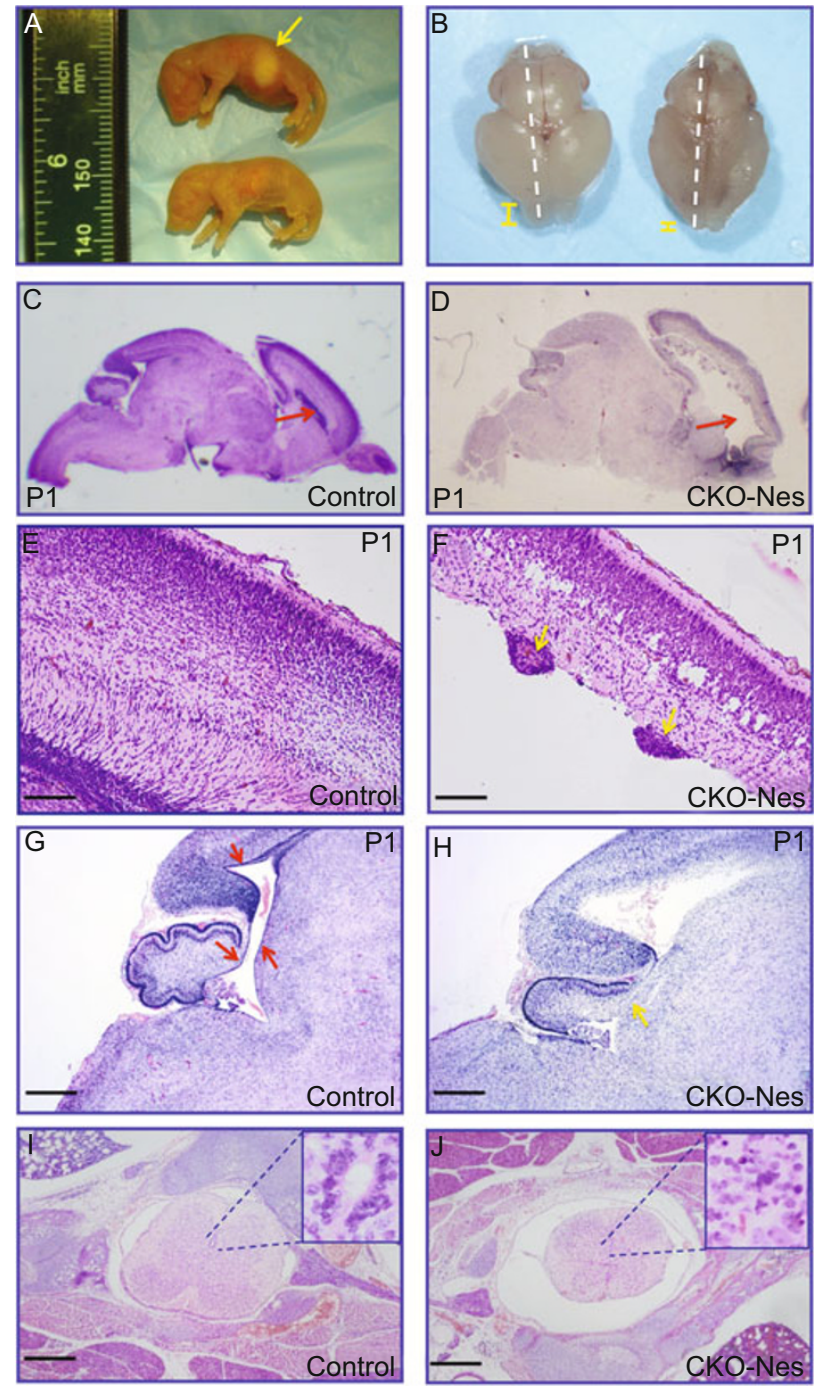

Figure 2. Deletion of Cdc42 in neuroepithelial cells leads aqueduct of Syvious closure and hydrocephaly. (A) A wholebody image of $\mathrm{P} 1 \mathrm{CKO}-\mathrm{Nes}$ (bottom) and its littermate control (above). A milk-filled stomach (indicated by yellow arrow) was only presented in the control pup. (B) The CKO-Nes (right) olfactory bulb size (highlights by yellow lines) is reduced and cerebral cortex is flat compared to the control brain (left). Dashed lines indicate the sagittal section plane in the panels $C$ and $D$. (C and D) Sagittal sections show the enlargement of lateral ventricle (indicates by red arrow) in CKO-Nes (D), but not in the control (C). ( $E$ and $F$ ) At high magnification, the thickness of cerebral cortex was reduced in CKO-Nes $(F)$, compared to control $(E)$. Note the accumulated ependymal cells in CKO-Nes (yellow arrows) (F). (G and $H$ ) Ependymal cells (dark blue indicated by red arrows) line the inside of third ventricle and patent aqueduct $(\mathrm{G})$. Ependymal cells in CKO-Nes are disappeared and aqueduct is closure (yellow arrow) $(\mathrm{H})$. (I and J) Histological analysis of spinal cord. Wellorganized central canal in control spinal cord $(\mathrm{I})$ and disorganized central canal in CKO-Nes spinal cord (J). Scale bar: $50 \mu \mathrm{m}$.

most remarkable finding was that the CKO-Nes mice exhibited bilateral ventricle enlargement with cerebral cortex hypoplasia 
(i.e. one of the characteristics of hydrocephaly) (Fig. 2D), compared to its littermate control (Fig. 2C). Higher power magnification of the cerebral cortex in the CKO-Nes mice showed that it was much thinner compared to the control mice, and that the ventricular and sub-ventricular zones had essentially disappeared. A clustering of the ependymal cells was also evident in the CKO-Nes mice (Fig. 2F). In contrast, the control brain showed well-organized cortical zones (Fig. 2E). The aqueduct of Sylvius, which appears as a long thin structure in the brain, connects the third and fourth brain ventricles. Defects in the structure of the aqueduct of Sylvious (stenosis and/or closure) represent one of the major underlying causes of hydrocephalus and so we performed serial sections to examine the aqueduct of Sylvius structure. Histological analysis showed that the aqueduct of Sylvius displayed stenosis and was essentially closed in the CKO-Nes brain. In addition, the ependymal cells which line the inside of the third ventricle and aqueduct were absent. Consistent with this observation of aqueduct closure, we also found that the third ventricle was dilated in CKONes brain (Fig. 2H). In contrast, the control mice showed the ependymal cells lining the inside of the third ventricle and the aqueduct of Sylvius, as well as the patency aqueduct (Fig. $2 \mathrm{G}$.

Because Nestin-Cre was not only expressed in the brain, but also in the spinal cord (Haigh et al., 2003), we decided to examine the role of $\mathrm{Cdc} 42$ in spinal cord development. Histological analyses of spinal cords harvested from control and CKO-Nes mice were performed one day after birth. In the control spinal cords, we observed the typical butterfly structure with the patency central canal in the middle. A single layer of pseudo-stratified ependymal cells exhibited a radial distribution around the lumen of the central canal (Fig. 2I). In the CKO-Nes spinal cords, the central canal was collapsed and lacked of differentiated ependymal cells (Fig. 2J). Together these data indicate that $\mathrm{Cdc} 42$ is pivotal for the differentiation of ependymal cells, and that the inactivation of $\mathrm{Cdc} 42$, by disrupting ependymal cell differentiation, gave rise to hydrocephaly.

\section{Deletion of Cdc42 in neuroepithelial cells causes cerebral cortex hypoplasia}

Although the CKO-Nes pups were born alive, severe abnormalities in the cerebral cortex suggest that Cdc42 plays a pivotal role in embryonic brain development. To explore these functions of Cdc42, we harvested embryos from timed-pregnant female mice between E14.5 and E16.5 and performed histological analysis. At E14.5, we observed a well-developed laminated structure of the cerebral cortex in control mice (Fig. $3 \mathrm{~A})$. A majority of nuclei in the ventricular zone showed apicalbasal polarity and the cells lining the lateral ventricles showed a prominent eosinophilic apical membrane staining (Fig. 3C). A laminated structure was still evident in the cere- bral cortex of CKO-Nes mice, although the cell numbers were increased slightly (Fig. 3B). Two groups of cells (marked by yellow arrows in Fig. $3 \mathrm{~B}$ ) lost their polarity and their apical membrane
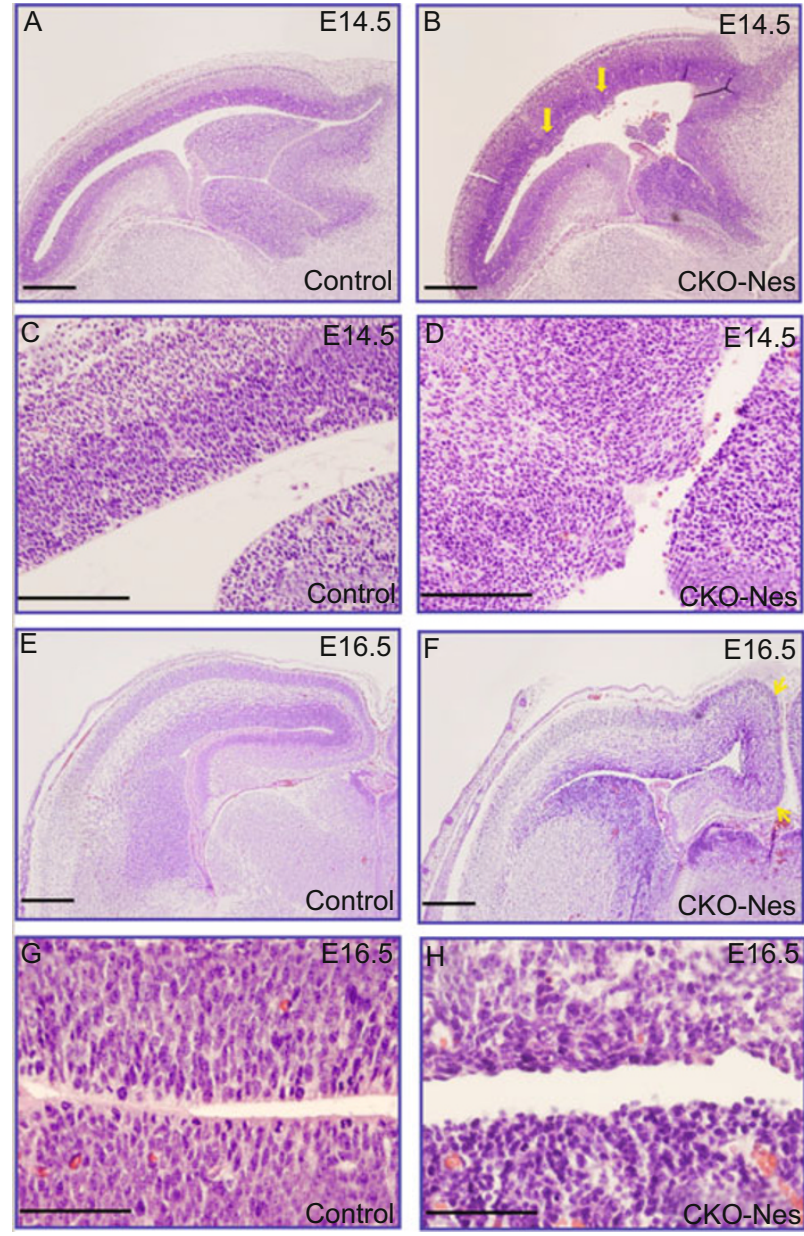

Figure 3. Neuronal cell polarity is disrupted in CKO-Nes cerebral cortex. E14.5 (A-D) and E16.5 (E-H) cerebral cortex coronal sections were stained by H\&E. E14.5 control cerebral cortex showed laminated structure in the lateral ventricle (A). High magnification shows a prominent eosinophilic apical membrane staining inside the cerebral cortex and majority neuronal cells display apical-basal polarity $(C)$. The most notable phenotype in E14.5 CKO-Nes brain is that two groups of cells (marked by yellow arrows) protruded into the ventricle and lost the eosinophilic menmbrane and apical-basal polarity characters ( $B$ and $D$ ). E16.5 control cerebral cortex showed distinct layers and neuronal cells exhibited basal-apical polarity (E and G). CKO-Nes cerebral cortex displayed unusual angle (marked by yellow arrows) and neuronal cells lost their polarity and cell numbers decreased significantly $(\mathrm{F}$ and $\mathrm{H})$. Scale bar: $50 \mu \mathrm{m}$.

domains were non-existent, suggesting that the inactivation of $\mathrm{Cdc} 42$ in neuronal epithelial cells caused the disruption of ventricular zone cell polarization (Fig. 3D). At E16.5, the cortical plate cell number of the CKO-Nes mice decreased dramatically (Fig. 3F), compared to that of the control mice (Fig. 3E). We noticed that the cell numbers in the ventricular zone were also decreased dramatically in CKO-Nes mice. In addition, the neocortex exhibited an abnormal orientation in the brains 
of CKO-Nes mouse embryos (indicated by yellow arrows), indicating that a folding problem occurred in the CKO-Nes neocortex (Fig. 3F). High magnification showed that all of the neuronal cells that lined the lateral ventricles lost their apical membrane domain and all of the nuclei in the ventricular zone lost their apical-basal direction (Fig. 3G), compared to controls (Fig. 3H).

\section{Cdc42 is essential for maintaining neuronal progenitors in the ventricular surface}

To gain insights into the potential mechanisms of hypoplasia in the cerebral cortex of CKO-Nes mice, we examined cell proliferation and cell survival at several stages. During cerebral cortex development, neural progenitors line the ventricular surface. We harvested brains from E14.5 to E16.5 and then performed coronal sections. Comparable sections were stained by phosphorylated histone $\mathrm{H} 3(\mathrm{p}-\mathrm{H} 3)$, a mitosis marker that recognizes neuronal progenitor cells. The $\mathrm{p}-\mathrm{H} 3$ positive cells were located at the ventricular zone facing to the lumen of lateral ventricles in E14.5 control mice (Fig. 4A). Although a majority of the p-H3-positive cells were located at the edge of the ventricular zone, some cells were sporadically located in the basal ventricular zone and subventricular zone in E14.5 CKO-Nes mouse brains (Fig. 4B). High magnification showed that the $\mathrm{p}-\mathrm{H} 3$-positive cells lined the ventricular surface in control (Fig. 4C) and CKO-Nes mouse brains (Fig. 4D). At E16.5, there were still abundant $\mathrm{p}$-H3-positive neural progenitors lining the ventricle surface (Fig. 4E). In contrast, the p-H3 positivecells were displaced from the ventricular surface and presented randomly in the basal ventricular and subventricular zone in the brains of CKO-Nes mice (Fig. 4F). High magnification images of control and CKO-Nes mouse brains are shown in Fig. 4G and $4 \mathrm{H}$. These data suggest that $\mathrm{Cdc} 42$ is essential for maintaining the neural progenitors at the lateral ventricular surface.

Based on in vitro studies, Cdc42 plays an important role in cell survival (Linseman and Loucks, 2008). To examine the role of Cdc42 in neuronal survival, we performed terminal deoxynucleotidyl transferase biotin-dUTP nick-end labeling (TUNEL staining) of the cerebral cortex in CKO-Nes mice and in controls. We found TUNEL-positive cells in both control and CKONes brains (data not shown). However, the TUNEL-positive cell numbers were comparable between control and CFKO-Nes, indicating that $\mathrm{Cdc} 42$ plays a dispensable role in cell survival.

\section{Deletion of Cdc42 impairs interkinetic nuclear migration}

Radial glial cell nuclei move to the basal side of the ventricle during $\mathrm{G} 1$ phase and then return to the ventricular surface after completing $S$ phase where they remain for mitosis (Gotz and Huttner, 2005). Several lines of evidence have shown that microtubule-associated proteins are important for interkinetic nuclear migration (INM), and that Cdc42 is a key regulator for microtubule reorganization (Spear and Erickson, 2012). We performed labeling experiments with bromo- deoxyuridine (Brdu) to examine whether $\mathrm{Cdc} 42$ is involved in the regulation
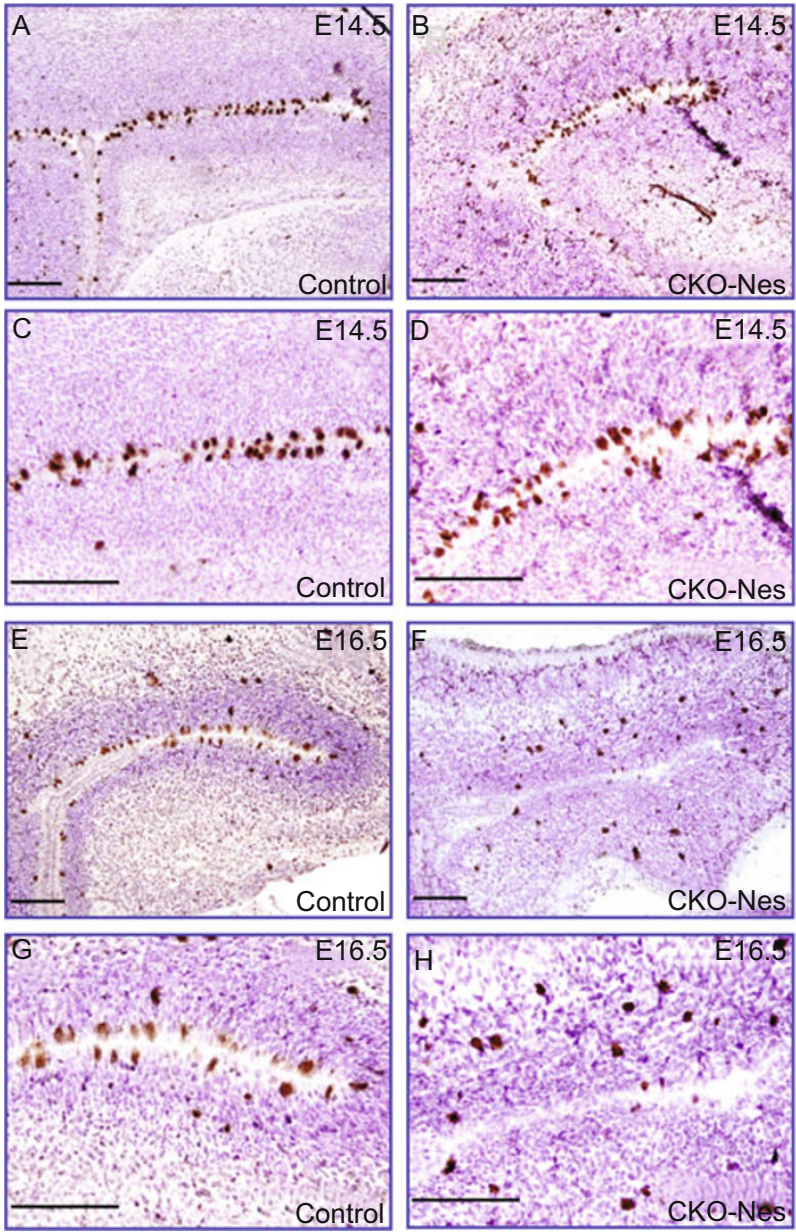

Figure 4. Decreased apical neuronal progenitor cell numbers in CKO-Nes cerebral cortex. Embryonic cerebral cortex was stained with antibodies against $\mathrm{p}-\mathrm{H} 3$ in $\mathrm{E} 14.5$ (A-D) and $\mathrm{E} 16.5$ (E$\mathrm{H})$ samples. $\mathrm{P}-\mathrm{H} 3$ positive neuronal progenitors lined up the ventricle surface in E14.5 control (A and C) and CKO-Nes (B and D) cerebral cortex. $\mathrm{P}-\mathrm{H} 3$ positive nuclear randomly distributed in the ventricular surface and subventricular zone in E16.5 CKO-Nes ( $F$ and $H$ ), and only presented in the ventricular surface in control brain ( $E$ and $G$ ). Scale bar: $50 \mu \mathrm{m}$.

of INM. Brdu was injected into E14.5 pregnant female mice and embryos were harvested 30 min later. Immunohistochemistry $(\mathrm{IHC})$ staining showed that Brdu-positive nuclei localized at the basal side of the ventricle zone in both control (Fig. 5A) and CKO-Nes mice (Fig. 5B). A high magnification image also showed a similar pattern for Brdu-positive cells in control (Fig. 5C) and CKO-Nes mice (Fig. 5D). At E16.5, the Brdu-positive nuclei were still located at the basal side of the ventricular zone in control mice (Fig. 5E). In contrast, Brdu-positive cells were scattered throughout the ventricular zone in CKO-Nes brains (Fig. 5F). Closer examination showed that the nuclei in CKO-Nes brains (Fig. $5 \mathrm{H}$ ) were less elongated along the apical-basal axis compared to those in control brains (Fig. 5G), suggesting that $\mathrm{Cdc} 42$ is a key regulator for INM during brain development. 

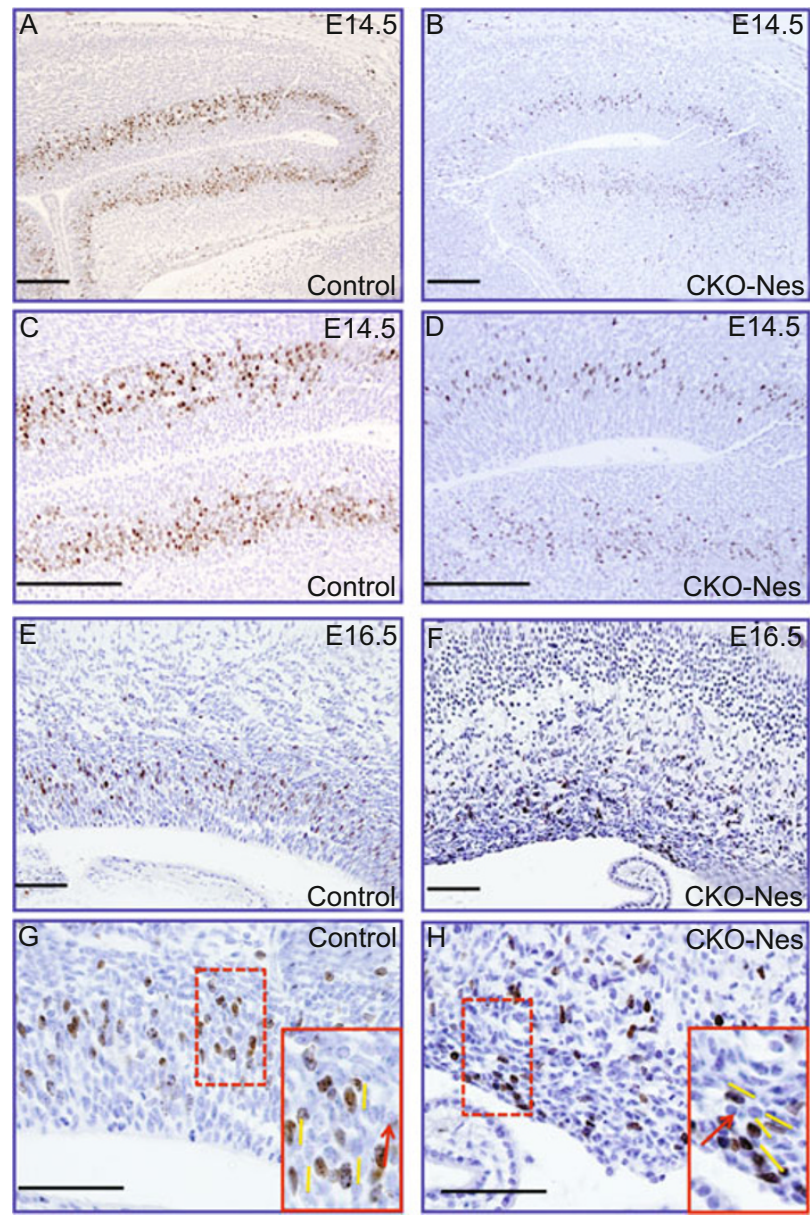

Figure 5. Interkinetic nuclear migration defects in CKO-Nes cerebral cortex. E14.5 (A-D) and E16.5 (E-H) cerebral cortex coronal sections were stained with antibodies against Brdu 30 min after Brdu intraperitoneal injection. The Brdu positive nuclei in E14.5 control ( $A$ and $C$ ) and CKO-Nes (B and D) sections migrated to subventricular zone. E16.5 CKO-Nes ( $\mathrm{F}$ and $\mathrm{H}$ ) Brdu positive nuclei randomly distributed in the ventricular surface and subventricular zone, and all the Brdu positive nuclei in the control cerebral cortex migrated into the subventricular zone ( $E$ and $G)$. The inserts in the panels $\mathrm{G}$ and $\mathrm{H}$ showed high magnification images and red arrows indicate the apical-basal direction. The yellow lines represent the long axial direction of nuclei. Scale bar: $50 \mu \mathrm{m}$.

Inactivation of Cdc42 in radial glial cell leads to hydrocephalus in adult mice

Inactivation of Cdc42 in neuroepithelial cells caused mice died in postnatal stage and made it impossible to study Cdc42 functions in adult mice brain. To explore the role of Cdc42 in adult mice brain, we created a second mouse line to inactivate Cdc42 in radial glial cells by crossing our Cdc42/flox mice with GFAP-Cre mice (Zhuo et al., 2001). The CKO-GFAP mice were viable and appeared normal until two weeks after birth. However, 4-week-old CKO-GFAP mice displayed domeshaped skulls (Fig. 6A). More than $50 \%$ of the CKO-GFAP mice died before they were 3 months old due to severe hydrocephalus (Fig. 6B). Histological analysis showed dramatically enlarged lateral ventricles and the cerebral cortex was thinner in the CKO-GFAP brains (Fig. 6D) compared to those of control mice (Fig. 6C). A percentage of the CKO-GFAP mice did not exhibit an obvious enlargement of the cranium, however, histological analysis showed the enlarged lateral ventricles and the third ventricle (data not shown). Hematoxylin and eosin (H\&E) staining showed that the ependymal cells lined the lateral and third ventricle in control mice (Fig. 6E). However, the ependymal cells in CKO-GFAP were detached from the ventricle (Fig. $6 F$ ). Consistent movement of cilia at the surface of ependymal cells is important to maintain cerebral spinal fluid (CSF) circulation and disruption of cilia function can induce hydrocephalus. To examine the cilia development in Cdc42 knock-out mice, we stained for a marker protein for cilia (vimentin) and found strong signals in control mice (Fig. 6G). In contrast, vimentinstaining in CKO-GFAP mice was non-existent (Fig. 6H). Taken together, these results suggest that $\mathrm{Cdc42}$ plays a pivotal role in radial glial cells and that the inactivation of $\mathrm{Cdc42}$ in these cells leads to hydrocephalus.

\section{Inactivation of Cdc42 in glial cells induced fried egg morphology change}

Glial cells are the most abundant cell types in the brain and provide support and nutrition for neurons. However, the functions of $\mathrm{Cdc42}$ in glial cells are still not clear. To explore the role and mechanisms of $\mathrm{Cdc} 42$ in glial cells, we isolated glial cells from the brains of E18.5 CKO-Nes mice. Western blotting showed that the expression levels for Cdc42 were decreased in CKO-Nes glial cells, compared to control cells (Fig. 7A upper panel). GFAP blotting suggested that the cells iso-lated from the brain maintained glial cells characteristics (Fig. 7A middle panel). Vinculin blotting served as a loading control (Fig. 7A bottom panel). When glial cells were plated for $24 \mathrm{~h}$, the majority of the control glial cells $(90 \%)$ showed the characteristic fibroblast morphology (Fig. 7C and 7D). However, more than $50 \%$ of the Cdc42-null glial cells showed 'fried egg' morphology (Fig. 7B and 7D), indicating Cdc42 plays a critical role in regulating glial cell cytoskeleton remodeling.

\section{DISCUSSION}

The establishment of a polarized cellular morphology is of fundamental importance for neural tube morphogenesis and brain development (Lubarsky and Krasnow, 2003; Klezovitch et al., 2004; Nechiporuk et al., 2007). Cdc42 has been shown to be essential for the establishment of cell polarity in multiple types of cells (Etienne-Manneville, 2004). Specific inactivation of Cdc42 in earlier (E10-E11.5) embryonic telencephalon disrupted neuronal polarity and changed ventral neural progenitor fate and induced holoprosencephaly (Fig. 8 S1) (Cappello et al., 2006; Chen et al., 2006). Consistent with previous studies, we found that inactivation of $\mathrm{Cdc} 42$ disrupted neuron polar- 

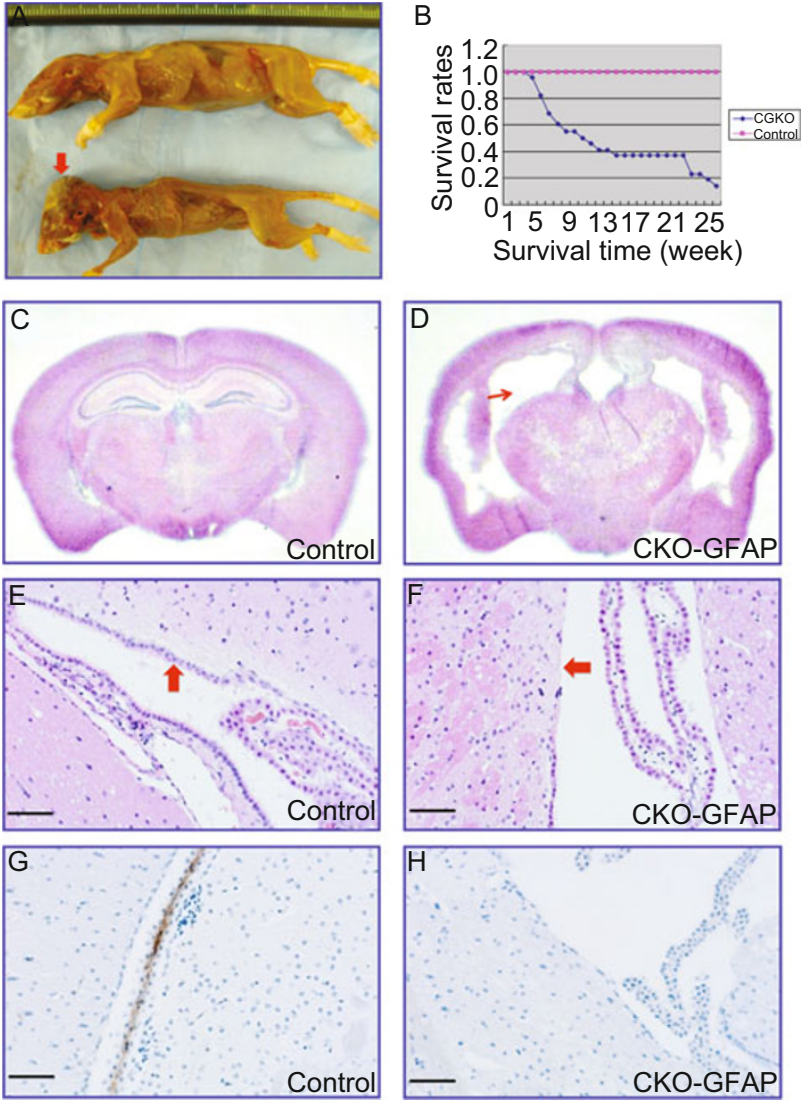

Figure 6. Inactivation of Cdc42 in radial glial cells induces hydrocephaly and ependymal cell denudation in adult mice. (A) Lateral view of 4-week-old mice shows a domed head (red arrow) in CKO-GFAP (bottom), but not in its control littermate (upper). (B) CKO-GFAP mice exhibit moribund or died began from 4-week-old and more than 60\% CKO-GFAP died before 4 months old. (C and D) H\&E stained 6-week-old brain coronal sections in control (C) and CKO-GFAP (D). CKO-GFAP presents obviously dilated lateral ventricle (red arrow) (D). Lateral ventricle surface was covered by ependymal cells (red arrow) in the control brain $(n=3)(E)$ and partially denudated in the CKO-GFAP brain $(n=$ 4) $(F)$. Immunostaining of vimentin show strong signals in control ependymal cells $(G)$, but not in CKO-GFAP ependymal cells $(H)$. Scale bar: $50 \mu \mathrm{m}$.

ity and decreased ventricular surface progenitor numbers. Because only apical progenitors which locate in the ventricle surface have self-renewing capability, the fate changes of apical progenitor results in depletion of apical progenitors in the later embryonic brain development and caused hypoplasia in cerebral cortex (Fig. 8 S2). In addition, the running out off neural progenitors also interfered of ependymal cell differentiation and caused aqueduct of Syvious stenosis and hydrocephaly (Fig. 8 S3). Furthermore, the deletion of Cdc42 in radial glial cells caused hydrocephalus in adult mice with ependymal cell denudation (Fig. 8 S4), suggesting that Cdc42 plays an indispensable role in radial glial cells during brain development.

Ependymal cells are a form of highly polarized pseudo-
A
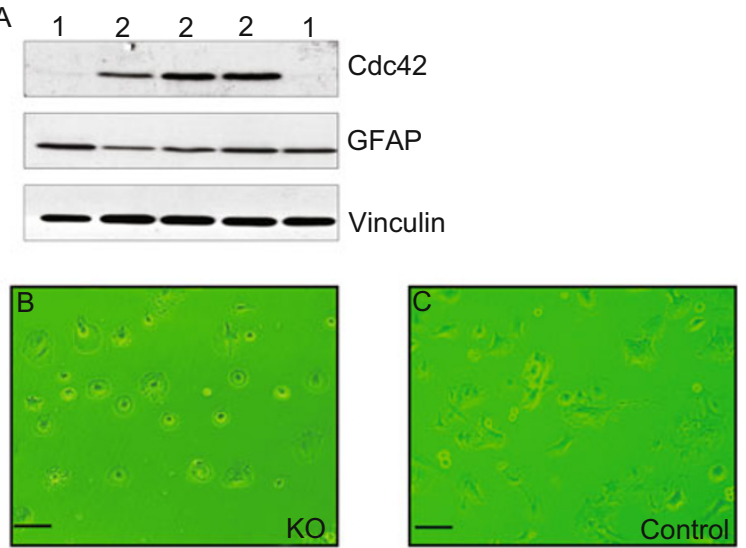

D

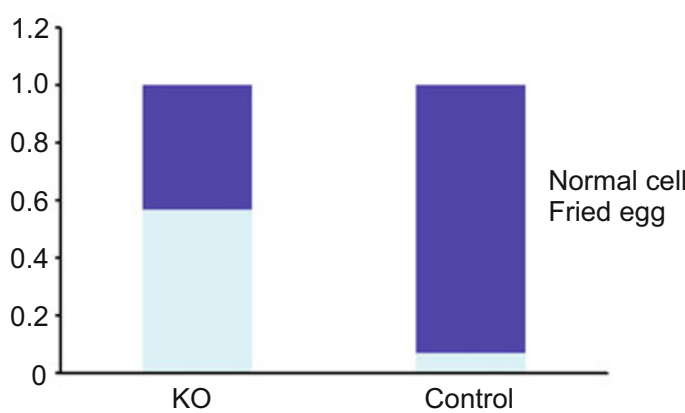

Figure 7. Morphological changes in cultured Cdc42-null glial cells. Glial cells were isolated from E18.5 CKO-Nes (marked as 1) or control brain (marked as 2) and cultured. Cell lysates were harvested and analyzed by Western blotting using Cdc42, GFAP and Vinculin antibody, respectively (A). After plating cells on a dish for $24 \mathrm{~h}, \mathrm{Cdc} 42$-null glial cells showed fried egg morphology (B) and control glial cells displayed typical fibroblast morphology (C) Three experiments data were quantified (D). Scale bar: $20 \mu \mathrm{m}$.

stratified epithelial cells that line the lumen of brain ventricles and the spinal cord central canal. Ependymal cilia are hairlike organelles and their movement is critical for generating a laminar cerebral spinal fluid (CSF). Abnormal cilia functions are displayed in hydrocephalus patients and inactivation of the cilia protein Mdnah5 in mice induced aqueduct closure and hydrocephalus (Ibanez-Tallon et al., 2002; Ibanez-Tallon et al., 2004). Recent study by Garvalov, et al. has shown that the inactivation of Cdc42 by Nestin-Cre induced lateral ventricle enlargement and neuronal tract defects (Garvalov et al., 2007). However, the mechanisms causing the enlargement of the lateral ventricle remain un-clear. Here we show that the inactivation of $\mathrm{Cdc42}$ in neuronal epithelial cells induced hydrocephalus with ependymal cell differential defects in both the brain and spinal cord. Loss of functional ependymal cells may have disrupted the aqueduct flow and caused its closure, thus blocking CSF circulation. Due to the fact that ependymal cells stem from radial glial cells (Spassky et al., 2005), we also analyzed CKO-GFAP mice. Although GFAP-Cre expressed as early as E13.5, we found that the Cdc42 expression levels were decreased beginning at E16.5. However, we observed differenti- 


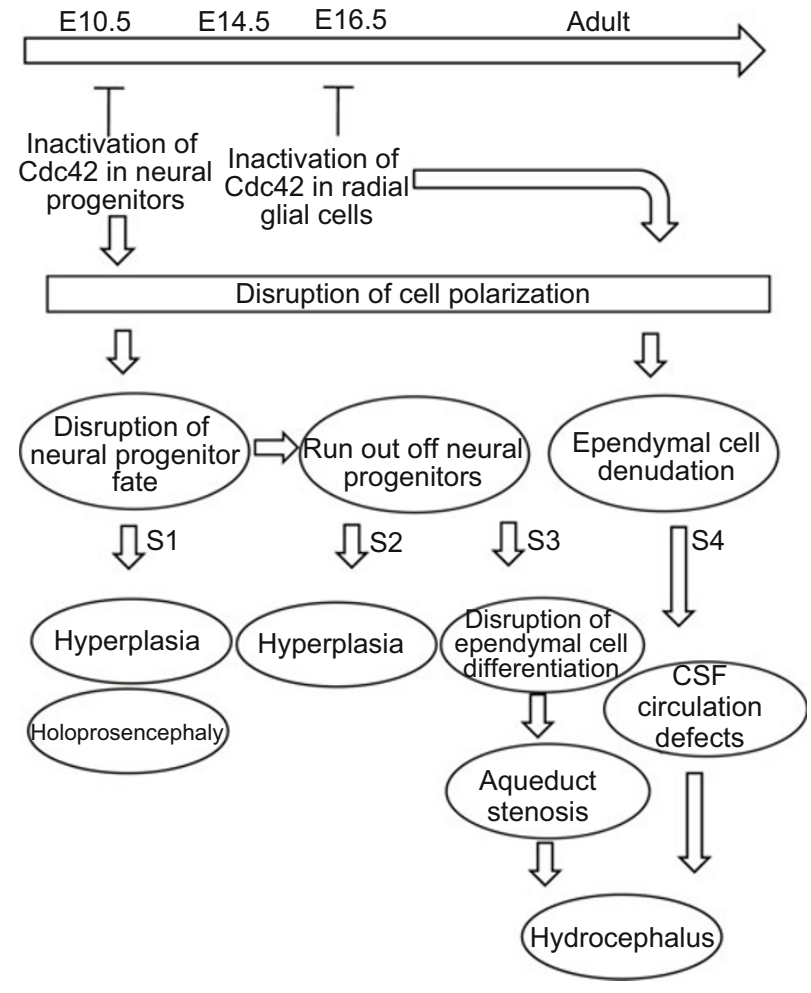

Figure 8. Diagram of Cdc42 inactivation in neuroepithelial cells or radial glial cells affects brain development. The deletion of Cdc42 in embryonic brain disrupted cell polarity. As a consequence, in earlier embryonic telencephalon (E10), the loss of cell polarity changed ventral neuronal progenitor fate and induced holoprosencephaly (stage 1, S1). In later embryonic brain (E16.5), the loss of neural progenitor cells caused cerebral hypoplasia (S2). Ependymal cell differentiation defects induced stenosis of aqueduct of Sylvius and hydrocephaly (S3). In adult mice brain, the deletion of $\mathrm{Cdc} 42$ in radial glial cells influenced the maintenance of ependymal cells and induced hydrocephaly (S4). CSF: cerebral spinal fluid.

ated ependymal cells lining the ventricle and central canal surface in neonatal CFKO-GFAP mice (data not shown). These results suggested that the deletion of Cdc42 in radial glial cells is not sufficient to disrupt the differentiation of ependymal cells, therefore indicating that neural cells also play an important role in the differentiation of ependymal cells. We should point out that we cannot totally exclude the possibility that GFAP-Cre does not provide a complete inactivation of $\mathrm{Cdc} 42$ in glial cells, and that the small amount of remaining Cdc42 can support their differentiation into ependymal cells. Interestingly, we observed hydrocephalus with ependymal cell denudation in adult CKO-GFAP mice, indicating that not only is Cdc42 important for ependymal cell differentiation, but it also plays an indispensable role in the maintenance of polarized ependymal cells.

Loss of cell polarity can increase cell proliferation and is a key step in tumor metastasis (Wodarz and Nathke, 2007). Inactivation of Lgl in the brain disrupted neuroepithelial cell polar- ity and increased neural progenitor cell proliferation as well as formed rosette-like structures, a non-specific feature of brain tumors (Klezovitch et al., 2004). Previous studies have shown that the inactivation of Cdc42 in embryonic brain induced hyperplasia in earlier brain development (Cappello et al., 2006; Chen et al., 2006). We were curious to know whether the inactivation of $\mathrm{Cdc} 42$ in neuroepithelial cells was capable of causing hyperplasia and possibly inducing the formation of brain tumors in later embryonic development or in adult mice. Surprisingly, we found that the deletion of Cdc42 in neuroepithelial cells caused hypoplasia in cerebral cortex in mid/later brain development. The reason for these contradictory results is that Cdc42 is important for the regulation of neuron progenitor fate and maintains the neuronal progenitors in the ventricular surface. When Cdc42 was inactivated, the neural progenitor cells left the ventricular surface. Although the cell numbers can increase in a relatively short period of time, neuronal progenitor cells will lose their progenitor characteristics and cannot continuously proliferate, thus resulting in hypoplasia in the mid/ later developmental stage (Fig. 8 S2). In our studies, we also showed hydrocephaly in CKO-Nes mice, making it important to clarify whether cerebral cortex hypoplasia is a direct effect from the inactivation of $\mathrm{Cdc} 42$ in the brain or only a secondary defect from hydrocephalus. Our data suggest that hypoplasia is a direct effect since we found that it occurs earlier than the onset of hydrocephalus. In CKO-GFAP mice, there was no apparent hydrocephalus in the embryonic brain, whereas the cerebral cortex hypoplasia was already detectable. Lgl knockout mice also showed hydrocephalus, however, the cerebral cortex exhibited hyperplasia (Klezovitch et al., 2004), indicating that hydrocephalus does not necessarily accompany cerebral cortex hypoplasia.

Mouse brain development involves both neurogenesis and gliogenesis. Previous studies have shown that the inactivation of Cdc42 in neuroepithelial cells caused defects in neuronal axon formation due to the disruptions of cytoskeletal organization (Garvalov et al., 2007). However, the function of Cdc42 in glial cells remains unclear. In the current study, using cultured glial cells, we show that the deletion of Cdc42 in glial cells affects cytoskeletal structure, suggesting that the inactivation of Cdc42 in glial cells also contributes to defects in the development of the brain in Cdc42-null mice.

\section{MATERIALS AND METHODS}

Construction of the targeting vector and generation of Cdc42 floxed mice

An isogenic $129 \mathrm{SvJ}$ mouse BAC clone containing genomic Cdc42 was identified by Southern blotting. A targeting vector was then constructed by inserting two loxP sites to flank the exon 2 of Cdc42 gene. The linearized targeting vectors were electroporated into E14.1 embryonic stem (ES) cells and the recombinant clones were subsequently injected into blastocyst to produce $\mathrm{Cdc} 42^{\text {flox[neo]/+ }}$ mice. The $\mathrm{Cdc} 42^{\text {flox[neo] }]+}$ mice were crossed with Ella-Cre to remove the neomycin cassette and then crossed with wild-type C57BL/6 mice to separate ElIA-Cre al- 
lele with Cdc42/flox allele. Nestin-Cre (B6.Cg-Tg(Nes-cre)1Kln/J) and GFAP-Cre (FVB-Tg(GFAP-cre)25Mes/J) mice were purchased from Jackson Laboratory (Bar Harbor, ME). Mice were housed in a pathogen-free facility and handled in accordance with the principles of the Guide for the Care and Use of Laboratory Animals. All the protocols were approved by the Institutional Animal Care and Use Committee (IACUC) of Texas A\&M Health Science Center and Cornell University.

\section{Genotype analysis by PCR}

Mice tail and embryos were genotyped by PCR analysis of genomic DNA. The following primers were used for genotyping: P1 (5'-TGCCTCTACCTCCTAAGTGCTGGGA-3'), P2 (5'-AGAGGACCCTTACAGGCCTCTTCCA-3'), P3 (5'-CCCGTGTGCTGGGATTAAAGGTGTG-3') and P4 (5'-GGCAGGCAGGCAGGCAGGTAGG-3'). The combination of primer $\mathrm{P} 1$ and $\mathrm{P} 2$ amplifies a 206-bp fragment from wild type Cdc42 allele and a 412-bp fragment from Cdc42/flox allele. Platinum Taq DNA Polymerase purchased from Invitrogen was used for PCR screening and the PCR condition is 3 cycles at $94^{\circ} \mathrm{C}$ for $3 \mathrm{~min}, 67^{\circ} \mathrm{C}$ for $2 \mathrm{~min}$ and $72^{\circ} \mathrm{C}$ for $1 \mathrm{~min} ; 30$ cycles at $94^{\circ} \mathrm{C}$ for $1 \mathrm{~min}, 67^{\circ} \mathrm{C}$ for $1 \mathrm{~min}$ and $72^{\circ} \mathrm{C}$ for $1 \mathrm{~min} ; 1 \mathrm{cycle}$ at $72^{\circ} \mathrm{C}$ for $10 \mathrm{~min}$. The combination of Primer P3 and P4 amplifies a 494-bp fragment from Cdc42 deletion allele. Platinum Taq DNA Polymerase High Fidelity from Invitrogen was used for PCR analysis and its condition is 3 cycles at $94^{\circ} \mathrm{C}$ for $3 \mathrm{~min}, 64^{\circ} \mathrm{C}$ for $2 \mathrm{~min}$ and $72^{\circ} \mathrm{C}$ for $1 \mathrm{~min} ; 30$ cycles at $94^{\circ} \mathrm{C}$ for $1 \mathrm{~min}, 64^{\circ} \mathrm{C}$ for 1 $\min$ and $72^{\circ} \mathrm{C}$ for $1 \mathrm{~min} ; 1 \mathrm{cycle}$ at $72^{\circ} \mathrm{C}$ for $10 \mathrm{~min}$.

\section{Southern blotting}

Genomic DNA isolated from mouse lung using phenol/chloroform was digested with EcoRI, electrophoresed on $0.7 \%$ agarose gels and transferred to NYTRAN SuPerCharge nylon membrane using the alkaline methods (Peng et al., 2006). ${ }^{32} \mathrm{P}$ labeled probes were then used for detecting the floxed and wild-type Cdc42 alleles.

Histological and immunohistochemistry staining analysis

Embryos were harvested between E12.5 and E18.5 and fixed in 4\% paraformaldehyde for overnight. After dehydration, samples were embedded in paraffin wax, sectioned, and stained with hematoxylin and eosin (H\&E) according standard protocol. Immunohistochemistry staining was carried out following the protocol described previously (Peng et al., 2008). Vimentin (DAKO) was diluted to 1:200, and phosphorylated histone H3 (Ser10) (Upstate) was diluted to 1:100.

\section{Western blotting}

Cerebral cortex or brain tissues were harvested and lysated with RIPA buffer. Tissue lysates were cleared by centrifugation, and total protein concentration was determined using the Bio-Rad protein assay. The following antibodies were used for Western blots analysis: Cdc42 (Cell Signaling) 1:500, Rac-1 (Santa Cruz) 1:1000.

\section{Isolation of embryonic glial cells}

Mouse brain glial cells were isolated from E18.5 embryos using a modified trypsin digestion method. Pregnant female mice were euthanized by $\mathrm{CO}_{2}$ inhalation and the embryos' frontal brain were quickly removed and washed with cold PBS for three times. The harvested tissues were then cut into several chunks and incubated in the $0.05 \%$ trypsin digestion solution for $10 \mathrm{~min}$ for three times. The supernatant was transferred into a new container which contains DMEM with $10 \%$ FBS. After centrifugation, the cells were resuspended and cultured with DMEM with $10 \%$ FBS.

Interkinetic nuclear migration assay

Brdu (50 mg/kg) was administered to pregnant mice at E14.5 or E16.5. Two hours later, the embryonic brains were harvested and fixed in $4 \%$ paraformadyhydrate for overnight. Paraffin embedded samples were sectioned and stained with Brdu antibodies following the manufacture's (Zymed Laboratories Inc.) instruction, as described previously (Nagy et al., 2007).

\section{Statistical analysis}

Data are presented as mean \pm SE. Means were compared by 2-tailed Student's t-test. $P \leqslant 0.05$ is considered to be statistically significant.

\section{ACKNOWLEDGMENTS}

This research was supported by Texas A\&M Health Science Center startup grant and Scott \& White Research Grant 110016 (to X.P.), National Institutes of Health Grant GM047458 (to R.A.C.)

\section{REFERENCES}

Aoki, K., Nakamura, T., and Matsuda, M. (2004). Spatio-temporal regulation of Rac1 and Cdc42 activity during nerve growth factorinduced neurite outgrowth in PC12 cells. J Biol Chem 279, 713719.

Bokoch, G.M. (2003). Biology of the p21-activated kinases. Annu Rev Biochem 72, 743-781.

Cappello, S., Attardo, A., Wu, X., Iwasato, T., Itohara, S., WilschBrauninger, M., Eilken, H.M., Rieger, M.A., Schroeder, T.T., Huttner, W.B., et al. (2006). The Rho-GTPase cdc42 regulates neural progenitor fate at the apical surface. Nat Neurosci 9 , 1099-1107.

Cerione, R.A. (2004). Cdc42: new roads to travel. Trends Cell Biol 14, 127-132.

Chen, F., Ma, L., Parrini, M.C., Mao, X., Lopez, M., Wu, C., Marks, P.W., Davidson, L., Kwiatkowski, D.J., Kirchhausen, T., et al. (2000). Cdc42 is required for PIP(2)-induced actin polymerization and early development but not for cell viability. Curr Biol 10, 758-765.

Chen, L., Liao, G., Yang, L., Campbell, K., Nakafuku, M., Kuan, C.Y., and Zheng, Y. (2006). Cdc42 deficiency causes Sonic hedgehogindependent holoprosencephaly. Proc Natl Acad Sci U S A 103, 16520-16525.

Del Bigio, M.R. (1995). The ependyma: a protective barrier between brain and cerebrospinal fluid. Glia 14, 1-13.

Edwards, D.C., Sanders, L.C., Bokoch, G.M., and Gill, G.N. (1999). Activation of LIM-kinase by Pak1 couples Rac/Cdc42 GTPase signalling to actin cytoskeletal dynamics. Nat Cell Biol 1, 253259.

Erickson, J.W., and Cerione, R.A. (2001). Multiple roles for Cdc42 in cell regulation. Curr Opin Cell Biol 13, 153-157. 
Etienne-Manneville, S. (2004). Cdc42--the centre of polarity. J Cell Sci 117, 1291-1300.

Etienne-Manneville, S., and Hall, A. (2001). Integrin-mediated activation of Cdc42 controls cell polarity in migrating astrocytes through PKCzeta. Cell 106, 489-498.

Etienne-Manneville, S., and Hall, A. (2002). Rho GTPases in cell biology. Nature 420, 629-635.

Etienne-Manneville, S., and Hall, A. (2003). Cell polarity: Par6, aPKC and cytoskeletal crosstalk. Curr Opin Cell Biol 15, 67-72.

Fukata, M., Watanabe, T., Noritake, J., Nakagawa, M., Yamaga, M., Kuroda, S., Matsuura, Y., Iwamatsu, A., Perez, F., and Kaibuchi, K. (2002). Rac1 and Cdc42 capture microtubules through IQGAP1 and CLIP-170. Cell 109, 873-885.

Garvalov, B.K., Flynn, K.C., Neukirchen, D., Meyn, L., Teusch, N., Wu, X., Brakebusch, C., Bamburg, J.R., and Bradke, F. (2007). Cdc42 regulates cofilin during the establishment of neuronal polarity. J Neurosci 27, 13117-13129.

Gotta, M., Abraham, M.C., and Ahringer, J. (2001). CDC-42 controls early cell polarity and spindle orientation in C. elegans. Curr Biol 11, 482-488.

Gotz, M., and Huttner, W.B. (2005). The cell biology of neurogenesis. Nat Rev Mol Cell Biol 6, 777-788.

Govek, E.E., Newey, S.E., and Van Aelst, L. (2005). The role of the Rho GTPases in neuronal development. Genes Dev 19, 1-49.

Haigh, J.J., Morelli, P.I., Gerhardt, H., Haigh, K., Tsien, J., Damert, A., Miquerol, L., Muhlner, U., Klein, R., Ferrara, N., et al. (2003). Cortical and retinal defects caused by dosage- dependent reductions in VEGF-A paracrine signaling. Dev Biol 262, 225-241.

Hutterer, A., Betschinger, J., Petronczki, M., and Knoblich, J.A. (2004). Sequential roles of Cdc42, Par-6, aPKC, and Lgl in the establishment of epithelial polarity during Drosophila embryogenesis. Dev Cell 6, 845-854.

Ibanez-Tallon, I., Gorokhova, S., and Heintz, N. (2002). Loss of function of axonemal dynein Mdnah5 causes primary ciliary dyskinesia and hydrocephalus. Hum Mol Genet 11, 715-721.

Ibanez-Tallon, I., Pagenstecher, A., Fliegauf, M., Olbrich, H., Kispert, A., Ketelsen, U.P., North, A., Heintz, N., and Omran, H. (2004). Dysfunction of axonemal dynein heavy chain Mdnah5 inhibits ependymal flow and reveals a novel mechanism for hydrocephalus formation. Hum Mol Genet 13, 2133-2141.

Johnson, D.I., and Pringle, J.R. (1990). Molecular characterization of CDC42, a Saccharomyces cerevisiae gene involved in the development of cell polarity. J Cell Biol 111, 143-152.

Kesavan, G., Sand, F.W., Greiner, T.U., Johansson, J.K., Kobberup, S., Wu, X., Brakebusch, C., and Semb, H. (2009). Cdc42-mediated tubulogenesis controls cell specification. Cell 139, 791-801.

Kim, A.S., Kakalis, L.T., Abdul-Manan, N., Liu, G.A., and Rosen, M.K. (2000). Autoinhibition and activation mechanisms of the WiskottAldrich syndrome protein. Nature 404, 151-158.

Kim, M.D., Kolodziej, P., and Chiba, A. (2002). Growth cone pathfinding and filopodial dynamics are mediated separately by Cdc42 activation. J Neurosci 22, 1794-1806.

Klezovitch, O., Fernandez, T.E., Tapscott, S.J., and Vasioukhin, V. (2004). Loss of cell polarity causes severe brain dysplasia in Lgl1 knockout mice. Genes Dev 18, 559-571.

Lakso, M., Pichel, J.G., Gorman, J.R., Sauer, B., Okamoto, Y., Lee,
E., Alt, F.W., and Westphal, H. (1996). Efficient in vivo manipulation of mouse genomic sequences at the zygote stage. Proc Natl Acad Sci U S A 93, 5860-5865.

Linseman, D.A., and Loucks, F.A. (2008). Diverse roles of Rho family GTPases in neuronal development, survival, and death. Front Biosci 13, 657-676.

Lubarsky, B., and Krasnow, M.A. (2003). Tube morphogenesis: making and shaping biological tubes. Cell 112, 19-28.

Luo, L., Liao, Y.J., Jan, L.Y., and Jan, Y.N. (1994). Distinct morphogenetic functions of similar small GTPases: Drosophila Drac1 is involved in axonal outgrowth and myoblast fusion. Genes Dev 8, 1787-1802.

Machesky, L.M., and Insall, R.H. (1999). Signaling to actin dynamics. J Cell Biol 146, 267-272.

Nagy, T., Wei, H., Shen, T.L., Peng, X., Liang, C.C., Gan, B., and Guan, J.L. (2007). Mammary epithelial-specific deletion of the focal adhesion kinase gene leads to severe lobulo-alveolar hypoplasia and secretory immaturity of the murine mammary gland. The Journal of biological chemistry 282, 31766-31776.

Nechiporuk, T., Fernandez, T.E., and Vasioukhin, V. (2007). Failure of epithelial tube maintenance causes hydrocephalus and renal cysts in Dlg5-/- mice. Dev Cell 13, 338-350.

Nobes, C.D., and Hall, A. (1995). Rho, rac, and cdc42 GTPases regulate the assembly of multimolecular focal complexes associated with actin stress fibers, lamellipodia, and filopodia. Cell 81, 53-62.

Peng, X., Kraus, M.S., Wei, H., Shen, T.L., Pariaut, R., Alcaraz, A., Ji, G., Cheng, L., Yang, Q., Kotlikoff, M.I., et al. (2006). Inactivation of focal adhesion kinase in cardiomyocytes promotes eccentric cardiac hypertrophy and fibrosis in mice. J Clin Invest 116, 217-227.

Peng, X., Wu, X., Druso, J.E., Wei, H., Park, A.Y., Kraus, M.S., Alcaraz, A., Chen, J., Chien, S., Cerione, R.A., et al. (2008). Cardiac developmental defects and eccentric right ventricular hypertrophy in cardiomyocyte focal adhesion kinase (FAK) conditional knockout mice. Proc Natl Acad Sci U S A 105, 6638-6643.

Prehoda, K.E., Scott, J.A., Mullins, R.D., and Lim, W.A. (2000). Integration of multiple signals through cooperative regulation of the N-WASP-Arp2/3 complex. Science 290, 801-806.

Sarner, S., Kozma, R., Ahmed, S., and Lim, L. (2000). Phosphatidylinositol 3-kinase, Cdc42, and Rac1 act downstream of Ras in integrin-dependent neurite outgrowth in N1E-115 neuroblastoma cells. Mol Cell Biol 20, 158-172.

Schwamborn, J.C., and Puschel, A.W. (2004). The sequential activity of the GTPases Rap1B and Cdc42 determines neuronal polarity. Nat Neurosci 7, 923-929.

Shinjo, K., Koland, J.G., Hart, M.J., Narasimhan, V., Johnson, D.I., Evans, T., and Cerione, R.A. (1990). Molecular cloning of the gene for the human placental GTP-binding protein Gp (G25K): identification of this GTP-binding protein as the human homolog of the yeast cell-division-cycle protein CDC42. Proc Natl Acad Sci U S A 87, 9853-9857.

Spassky, N., Merkle, F.T., Flames, N., Tramontin, A.D., GarciaVerdugo, J.M., and Alvarez-Buylla, A. (2005). Adult ependymal cells are postmitotic and are derived from radial glial cells during embryogenesis. J Neurosci 25, 10-18.

Spear, P.C., and Erickson, C.A. (2012). Interkinetic nuclear migra- 
tion: a mysterious process in search of a function. Dev Growth Differ 54, 306-316.

Tronche, F., Kellendonk, C., Kretz, O., Gass, P., Anlag, K., Orban, P.C., Bock, R., Klein, R., and Schutz, G. (1999). Disruption of the glucocorticoid receptor gene in the nervous system results in reduced anxiety. Nat Genet 23, 99-103.

Wallingford, J.B. (2006). Planar cell polarity, ciliogenesis and neural tube defects. Hum Mol Genet 15 Spec No 2, R227-234.
Wodarz, A., and Nathke, I. (2007). Cell polarity in development and cancer. Nat Cell Biol 9, 1016-1024.

Wu, W.J., Erickson, J.W., Lin, R., and Cerione, R.A. (2000). The gamma-subunit of the coatomer complex binds Cdc42 to mediate transformation. Nature 405, 800-804.

Zhuo, L., Theis, M., Alvarez-Maya, I., Brenner, M., Willecke, K., and Messing, A. (2001). hGFAP-cre transgenic mice for manipulation of glial and neuronal function in vivo. Genesis 31, 85-94. 